\title{
Correction to: Gross primary production of dwarf bamboo, Sasa senanensis, in a mature beech forest with a substantial gap-mosaic structure
}

\author{
Yihan Cai ${ }^{1} \cdot$ Yosuke Tanioka $^{2} \cdot$ Toru Kitagawa $^{2} \cdot$ Hideyuki Ida $^{3} \cdot$ Mitsuru Hirota $^{4}(\mathbb{C}$
}

Published online: 22 March 2021

(C) The Botanical Society of Japan 2021

\section{Correction to: \\ Journal of Plant Research (2021) 134:209-221 \\ https://doi.org/10.1007/s10265-021-01262-y}

In the original publication of the article, one of the author names was published incorrectly as "Toru Kitawaga". The correct name is "Toru Kitagawa".

Publisher's Note Springer Nature remains neutral with regard to jurisdictional claims in published maps and institutional affiliations.

The original article can be found online at https://doi.org/10.1007/ s10265-021-01262-y.

Mitsuru Hirota

hirota0313@gmail.com

1 Graduation School of Science and Technology, University of Tsukuba, Tsukuba, Ibaraki, Japan

2 Graduate School of Life and Environmental Sciences, University of Tsukuba, Tsukuba, Ibaraki, Japan

3 Faculty of Education, Shinshu University, Nagano, Nagano, Japan

4 Faculty of Life and Environmental Sciences, University of Tsukuba, Tsukuba, Ibaraki, Japan 